\title{
Control prenatal en mujeres encarceladas embarazadas del Perú: análisis del primer censo nacional penitenciario
}

\section{Prenatal care in imprisoned pregnant women in Peru: analysis of the first national prison census}

Correspondencia Juan Carlos Ruiz Maza juancarlo.ruizmaza@gmail.com

Recibido: 31/01/2018 Aprobado: 21/02/2018

Citar como: Ruiz-Maza JC. Control prenatal en mujeres encarceladas embarazadas del Perú: análisis del primer censo nacional penitenciario. Acta Med Peru. 2018;35(1):75-6

\author{
Juan C. Ruiz-Maza1,2a \\ 1 Universidad Nacional Mayor de San Marcos. Lima, Perú. \\ 2 Sociedad Científica de San Fernando. Lima, Perú. \\ a Estudiante de Medicina Humana
}

Sr. Editor:

Las mujeres encarceladas embarazadas constituyen una población en riesgo dadas sus condiciones de vida y la deficiencia de apoyo social, lo que las predispone a presentar un control prenatal (CPN) inadecuado, lo que perjudica la salud del binomio madre-hijo ${ }^{[1]}$. Los informes de CPN son indicadores de la situación de salud y los servicios de salud de un país y pueden utilizarse para la toma de decisiones y ejecución de políticas preventivas ${ }^{[2]}$; estos informes son escasos en la población penitenciaria peruana, situación que motivó el desarrollo de esta investigación, cuyo objetivo fue describir la prevalencia de la realización de CPN en este grupo humano.

Estudio descriptivo que consistió en el análisis de la base de datos del Censo Nacional Penitenciario realizado en el años 2016 a todos los establecimientos penitenciarios peruanos, cuyos datos están disponibles en el sitio web del Instituto Nacional de Estadística e Informática (http://iinei.inei.gob. pe/microdatos/). Se evaluó la realización de CPN (sí/no), como variable principal, y las características sociodemográficas de los encuestados así como las razones para no realizar el CPN, como variables secundarias.

Los criterios de inclusión fueron ser mujer en edad fértil (15 a 49 años) y responder afirmativamente a las siguientes preguntas: "¿Se encuentra actualmente en estado de gestación?" y "¿Se confirmó mediante un examen de laboratorio/ultrasonido, antes de ingresar al sistema penitenciario?". EI CPN se evaluó con la pregunta: "¿Actualmente realiza control prenatal?". Y la causa de la falta de CPN se evaluó con la pregunta: "¿Por qué no realiza el control prenatal?".

Este estudio utilizó datos de una base de datos de dominio público en la que no hay información que permita conocer la identidad de los encuestados, preservando así la confidencialidad de los datos.

A nivel nacional, 42 mujeres encarceladas cumplieron con los criterios de inclusión. Veintiocho (67\%) reportaron realizar CPN y la prevalencia de este informe según características sociodemográficas, acceso a servicios de salud intrapenitenciarios, padecimiento de enfermedades y consumo de sustancias se describe en la Tabla 1. De las 14 mujeres embarazadas que informaron no haber tenido CPN, ocho (57\%) indicaron que la falta de CPN fue debido a la falta de dinero, cuatro (29\%) indicaron otras razones como no tener seguro de salud, no considerar necesario el CPN, recibir maltrato del personal de salud y no tener contacto con el personal de salud encargado. Los dos restantes (14\%) no especificaron una causa. 
Tabla 1. Informe de control prenatal en mujeres encarceladas embarazadas del Perú acorde a sus características sociodemográficas, seguro de salud, antecedentes patológicos y uso de sustancias, 2016.

$\begin{array}{ccc} & \text { Mujeres } & \text { Mujeres que } \\ & \text { embarazadas } & \text { realizaron controles } \\ \text { Variable } & \text { encarceladas } & \text { prenatales } \\ & (n=42) & (n=28) \\ & n(\%) & n(\%)\end{array}$

Estado civil

$\begin{array}{lcc}\text { Soltera } & 17(40) & 14(50) \\ \text { Conviviente } & 12(29) & 9(32) \\ \text { Casada } & 5(12) & 2(7) \\ \text { Divorciada/separada } & 8(19) & 3(11)\end{array}$

Edad (años)

$\begin{array}{ccc}18-24 & 16(38) & 15(54) \\ 25-29 & 13(31) & 4(14) \\ 30-34 & 3(7) & 2(7) \\ 35-39 & 7(17) & 5(18) \\ 40-45 & 3(7) & 2(7)\end{array}$

Número de hijos

$\begin{array}{lcc}\text { Ninguno } & 10(24) & 9(32) \\ 1 \text { a } 2 & 24(57) & 14(50) \\ 3 \text { a } 4 & 6(14) & 4(14) \\ \text { Más de } 4 & 2(5) & 1(4)\end{array}$

Nivel educativo

$\begin{array}{lcc}\begin{array}{l}\text { Sin estudios/ } \\ \text { primaria }\end{array} & 4(10) & 3(11) \\ \text { Secundaria } & 30(71) & 22(79) \\ \text { Superior } & 8(19) & 3(11)\end{array}$

Cuenta con seguro de salud

$\begin{array}{ccc}\text { Sí } & 38(90) & 26(93) \\ \text { No } & 4(10) & 2(7)\end{array}$

Asistencia a EESS penitenciarios

$\begin{array}{lll}\text { Sí } & 27(64) & 22(79) \\ \text { No } & 15(36) & 6(21)\end{array}$

Antecedente de

$\begin{array}{lcc}\begin{array}{l}\text { Hipertensión arterial } \\ \text { Infección de } \\ \text { transmisión sexual }\end{array} & 2(5) & 2(7) \\ \begin{array}{l}\text { Infección por VIH/ } \\ \text { SIDA }\end{array} & 2(10) & 4(14) \\ \begin{array}{l}\text { Uso de sustancias } \\ \text { psicoactivas }\end{array} & 22(52) & 12(43)\end{array}$

Fuente: Primer Censo Nacional Penitenciario 2016. Realización propia. EESS: establecimientos de salud.
Nuestros resultados indican un bajo nivel de realización del CPN en la población penitenciaria peruana, el cual es menor al de la población general (cerca del 97\%) ${ }^{[2]}$; además, este CPN es menos frecuente en quienes no cuentan con seguro de salud o no acuden a los establecimientos de salud dentro de los establecimientos penitenciarios. Estas situaciones han sido descritas anteriormente ${ }^{[3]}$ y estarían vinculadas a las condiciones económicas y sociales desfavorables que padece esta población, así como a la falta de desarrollo de las cárceles como lugares donde la cobertura del CPN podría mejorar gracias a intervenciones de salud pública ${ }^{[4]}$.

La realización del CPN varía de acuerdo con el estado civil y el número de hijos ${ }^{[5]} y$ demuestra la influencia del apoyo social y las experiencias en embarazos anteriores en la realización o no de un CPN en las mujeres embarazadas encarceladas. El hecho de que los antecedentes patológicos y el consumo de sustancias estén relacionados con la frecuencia del informe del CPN resalta la importancia de reforzar su acceso en donde se evaluaría completamente el embarazo y las enfermedades que afectan la salud de las mujeres embarazadas ${ }^{[4]}$.

Se concluye que existe una baja cobertura de CPN en mujeres encarceladas en el Perú. Se debe alentar el desarrollo de investigaciones que propongan estrategias efectivas para resolver esta situación.

Conflictos de interés: El autor declara no tener conflictos de interés.

\section{REFERENCIAS BIBLIOGRÁFICAS}

1. Fogel $\mathrm{Cl}$. Pregnant prisoners: impact of incarceration on health and health care. J Correct Health Care. 1995;2(2):169-90.

2. Saad-Haddad G, DeJong J, Terreri N, Restrepo-Méndez MC, Perin J, Vaz L, et al. Patterns and determinants of antenatal care utilization: analysis of national survey data in seven countdown countries. J Glob Health. 2016;6(1):010404.

3. Tanner R. Pregnancy outcomes at the Indiana women's prison. J Correct Health Care. 2010;16(3):216-9.

4. Bell JF, Zimmerman FJ, Cawthon ML, Huebner CE, Ward DH, Schroeder CA. Jail incarceration and birth outcomes. J Urban Health. 2004;81(4):630-44.

5. Walker JR, Hilder L, Levy MH, Sullivan EA. Pregnancy, prison and perinatal outcomes in New South Wales, Australia: a retrospective cohort study using linked health data. BMC Pregnancy Childbirth. 2014;14(1):214. 